Наиболее наглядно эта функция пролептических конструкций проявляется в использовании конструкций с обстоятельством времени в качестве обособленного компонента. Говорящий, вынося обстоятельственный признак в обособленную позицию, использует его в качестве исходного пункта для развертывания не одного, а двух предложений, соотнесенных с обособленным обстоятельством при помощи анафорического наречия «da». Причем говорящие используют этот прием не только в процессе формирования высказывания по ходу формулирования мысли, т. е. в процессе «саморедактирования»:

... jeden Jahr oder jeden Halbjahr, da wird eine Schulsprecherin gewählt, eine Unterstufensprecherin und eine Oberstufensprecherin, но и при необходимости добавления новых порций информации, когда форма складывающегося высказывания удовлетворяет говорящего:

Und manchmal, da gehen wir die Ideen aus, da weiß ich nicht mehr weiter.

Таким образом, пролептическая конструкция, выполняя в тексте важные коммуникативные функции, направленные на достижение определенных коммуникативных целей по отношению к собеседнику, является одним из структурно-семантических средств, облегчающих говорящему процесс порождения связного текста в условиях спонтанного общения. Именно по этой причине такие конструкции преобладают в детской речи.

По мере обогащения общего фонда знаний и повышения уровня языковой компетенции появляется все больше возможностей для использования тех или иных структурно-семантических средств при построении связного высказывания или текста. Соответственно соотношение этих средств в тексте может служить показателем уровня языковой компетенции индивида.

$$
* * *
$$

1. Адмони В. Г. Синтаксис современного немецкого языка. Л., 1987. С.176.

2. Маслов Ю. С. Введение в языкознание. М., 1997. С. 12-13.

3. Бахтин М. М. Проблема текста в лингвистике, филологии и других гуманитарных науках: Опыт философского анализа // Бахтин М. М. Литературно-сатирические статьи. М., 1986. С.475.

4. Эйхбаум Г. Н. Обособленные члены предложения в немецком языке. Л., 1994. С.21.

5. Hiesel E., Schendels E. Deutsche Stilistik. Moskau, 1985. S. 147.

\title{
Абдукадырова Т.T. \\ Речевые намерения как фактор развития коммуникативной компетенции в преподавании иностранного языка
}

ФГБОУ ВО «Чеченский государственный университет им. А.А. Кадырова»

(Россия, Грозньй)

doi: 10.18411/trnio-12-2021-209

\section{Аннотация}

Данная статья рассматривает актуальные проблемы общения, в теории речевых актов и ее универсальных понятий.

Основополагающую роль в стратегии общения играют пропозитивные и иллокутивные акты речевых намерений как фактор развития коммуникативной компетенции в преподавании иностранного языка.

Важность данной статьи обусловлена тем, что следует делать акцент на отборе языковых единиц для реализации коммуникативных намерений, ибо известно, что толерантность, проявляемая носителями языка на фонетическом, лексическом и грамматическом уровнях, обычно отсутствует в области коммуникативных прогнозов.

Ключевые слова: семиотика, иллокутивая единица, препозитивный акт, дискурс, синтаксис. 


\section{Abstract}

His article examines the actual problems of communication in the theory of speech acts and its universal concepts.

Prepositive and illocutionary acts of speech intentions play a fundamental role in the communication strategy as a factor in the development of communicative competence in teaching a foreign language.

The importance of this article is due to the fact that emphasis should be placed on the selection of language units for the implementation of communicative intentions, because it is known that the tolerance shown by native speakers at the phonetic, lexical and grammatical levels is usually absent in the field of communicative forecasts.

Keywords: semiotics, illocutionary unit, prepositive act, discourse, syntax.

Лингвистика, как семиотика, анализирует и описывает знаковый характер артикулируемых человеком звуков, равно как процессов их эмиссии и рецепции. Общая семиотика фиксирует три области отношений, которые слиты воедино в ситуации употребления знака, но в аналитико-методических целях могут быть названы порознь: синтаксис, семантика и прагматика. Наиболее полно исследованы и описаны синтаксис и семантика, чего нельзя сказать о прагматике. Между тем именно эта относительно новая область лингвистики непосредственно связана с разработкой стратегии общения, теории речевых актов и ее универсальных понятий - иллокутивная единица, препозитивный акт и дискурс.

Основными задачами прагматики называются такими, как исследование отношений между языковым знаком и неязыковым окружением под углом зрения, насколько это окружение обусловливает выбор языковых средств для реализации речевых намерений; исследование психологических условий речевого акта и коммуникативных ситуаций, возникающих в результате того, что говорящий и слушающий, владеющие общим языковым кодом, вступают друг с другом и с неязыковым окружением в определенные отношения; исследование универсалий, составляющих суть диалога как ведущей формы речевого общения, к которым относятся как языковые, так и паралингвистические знаки; исследование параметров, определяющих речевую ситуацию, таких, например, как отправитель и получатель информации, время и условия их общения, фонологосинтаксические качества высказывания и их когнитивное содержание, способы реализации говорящим своих интенций, умение и готовность партнеров по коммуникации к смене ролей «говорящий - слушающий» в соответствии с потребностями общения [3, с.102].

Известно, что в немецком языке, как и в русском, существуют две формы обращения - «ты» и «вы», однако в немецком отсутствует в обращении отчество, являющееся обязательным компонентом в русском языке, равно как в русском, в отличие от немецкого, не принято обращение по фамилии к учителю, коллеге, соседу по квартире. Или, скажем, использование пассива, объем значения которого, и сфера употребления в устной речи в русском и немецком языках различны [4, с.56].

Третья задача, наиболее сложная, связана с многослойностью процесса речевого акта, возникающей по той причине, что любой текст, в широком смысле слова, содержит пропозитивные утверждения, возможно - комментарии к ним, либо рефлексии об их содержании. Это делает тексте коммуникативным и метакоммуникативным одновременно.

Можно назвать целый ряд иллокутивных актов без пропозиции: формы приветствия, прощания - Guten Tag! Auf Wiedersehen или стереотипные обороты - Wie geht`s Ihnen? Hocherfreut!, но трудно найти примеры пропозиций без иллокуций, разве что заучивание наизусть, которые являются не чем иным, как искусственной продукцией пропозитивных актов без иллокутивных.

У обучающихся, как правило, отсутствует механизм интуитивного отбора каких-то речевых единиц, что мешает им порой привести в соответствие свои коммуникативные намерения с формой их вербализации. 
Так, например, сказанное Ich habe es doch gar nicht gehört в ответ на вопрос - Haben Sie es gehört? Прозвучит с упреком, как будто человек раздраженно опровергает кем-то высказанное утверждение, что он это слышал, чего в действительности не было. На такую речевую реакцию того, кому адресован вопрос, носитель языка предположительно может ответить - «Das hat ja auch niemand behauptet», вместо адекватного изначальной ситуации «Ach, soll» это будет свидетельством того, что коммуникация не состоялась, ибо не достигнуто взаимное понимание.

В другом контексте «doch» может придать повествовательному предложению вопросительный характер, который без данной модальной частицы полностью отсутствует. Так, например, Ich habe doch das gesagt. Ich habe das gesagt.

Модальная часть «Ја» в высказывании «Sie sollen ja dieses Buch gelesen haben «указывает на то, что речь идет скорее об упреке, почему книга до сих пор не прочитана. Употребление в вопросе mal предает предложению оттенок требования, а так называемые w -вопросы превращаются при введении модальной частицы в schon риторические. Сравните:

Wie viel Äpfel hat Jürgen? - Wie viel Äpfel hat schon Jürgen?

В вопросе: Wann war das nur?

Появление "Nur" свидетельствует о том, что он либо знал это раньше, либо должен был знать, а вставленное в повелительное предложение ruhig снимает резкий, угрожающий тон требования: Komm ruhig nach Hause.

Данные примеры свидетельствуют о том, с какой осторожностью следует подходить к отбору языковых единиц для реализации коммуникативных намерений, ибо известно, что толерантность, проявляемая носителями языка на фонетическом, лексическом и грамматическом уровнях, обычно отсутствует в области коммуникативных прогнозов.

Если признать бесспорным положение, что задачей преподавания иностранного языка является формирование коммуникативных навыков и умений, то напрашивается вывод о том, что обучать следует иллокуциям, составляющим, по сути дела, коммуникацию, в которой они находят свою экспликацию.

В этом плане определенный интерес представляет исследование Ю. Хабермаса, часть которого является собранное под рубрикой "Kommunikativa“" [6,c.10]. Konstantiva множество иллокутивных актов, позволяющих реализовать свои коммуникативные намерения, прежде всего в диалоге, и приводить в соответствие прагматический смысл реплик с их когнитивным использованием. Включенные сюда выражения и глаголы имеют что-то общее с аргументативным качеством разговора.

Характерно, что ни один из примеров, приведенных им, не представляет собой какойто языковой особенности, напротив, все они - обиходный, повседневный английский язык. Однако анализ текстов учебников, претендующих, как правило, на аутентичный английский язык, выявил отсутствие в них данных слов и выражений. Думается, что аналогичную картину можно получить и при анализе текстов, составляющих основу учебников немецкого языка. Такие описательные тексты сообщающего характера практически не содержат иллокуций, и не учат их использованию, в результате чего обучающиеся приобретают умения и навыки вербализации содержания, но не умеют сообразно ситуации завязать, продолжить, прервать, закончить разговор, что явилось бы коммуникацией в подлинном смысле этого слова.

Таким образом, прагматика заставляет нас по-новому взглянуть на задачи и содержание практики преподавания прежде всего иностранного языка. Вследствие того, что данная научная дисциплина занимается непосредственно анализом речи, измеряемой ею в таких единицах, как дискурс, она призвана дать определенные рекомендации по отбору языкового учебного материала и его организации. И, наконец, для методики преподавания было бы важным получить данные исследования прагматики в плане систематизации 
процесса употребления языковых знаков в речи с четким акцентом на дидактически релевантном понятии - практика языка.

1. Арутюнова Н. Д. Речевой акт // Лингвистический энциклопедический словарь. - М.: Советская энциклопедия, 1990. - 682c.

2. Боева - Омелечко Н.Б. Краткий толковый словарь социолингвистических терминов. - М. Готика, 2004. - 60с.

3. Винокур Т.Г. Говорящий и слушающий. Варианты речевого поведения. М.; Российская академия наук. Институт русского языка-Скан, обработка, формат: Николай Савченко, 2018.

4. Остин Дж. Слово как действие // Новое в зарубежной лингвистике: теория речевых актов. Вып. XVII. - M., 1996. С. 27.

5. Серль Дж. Что такое речевой акт // Новое в зарубежной лингвистике: теория речевых актов. Вып. XVII. - M., 1996. С. 151-169.

6. Х Хабермас Юрген. Моральное сознание и коммуникативное действие СПб: Наука, 2001.-. 377с.

\section{Алимханова М.X. \\ Метафорическая особенность средств выражения персуазивной коммуникации в немецком политическом дискурсе}

ФГБОУ ВО «Чеченский государственный университет им. А.А. Кадырова»

(Россия, Грозный)

doi: 10.18411/trnio-12-2021-210

\section{Аннотация}

Данная статья посвящена исследованию персуазивной коммуникации в политическом дискурсе и ее метафорической особенности. Образ политического мира, созданного человеком, изначально антропоцентричен: этот мир строится в сознании человека, который находится в концептуализации политических реалий на своих представлениях об отношениях между человеком и миром. Метафора реализует концепции человека как центра восприятия мира.

Ключевые слова: коммуникация, метафора, контекст, дискурс, концепт.

\section{Abstract}

This article is devoted to the study of persuasive communication in political discourse and its metaphorical features. The image of the political world created by man is initially anthropocentric: this world is built in the mind of a person who is in the conceptualization of political realities on his ideas about the relationship between man and the world. The metaphor realizes the concept of a person as a center of perception of the world.

Keywords: communication, metaphor, context, discourse, concept.

Как уже упоминалось ранее, много научных трудов посвящено исследователями персуазивной коммуникации.

Термин «персуазивная коммуникация переводится как «внушение», «пропаганда. Но до сих пор не получен ответ на вопрос, где проходит линия разграничения между понятиями «речевое воздействие». Все вышеназванные типы общения являются средствами языковой манипуляцией в процессе которого происходит по мнению Х. Грюнерта «ментальнокоммуникативное взаимодействие партнеров по общению, при котором адресат пытается повлиять на адресата и заставить его действовать» [31, с.67].

Данный факт показывает, насколько сложно провести четко определенное разграничение между вышеназванными терминами, но для достижения поставленной цели нашего исследования мы попытаемся прийти к соответствующим определениям.

Американский исследователь Г. Джоуетт считает, что понятие «пропаганда» является ментальной единицей коммуникации, а внушение — часть пропаганды. Коммуникация же, 